\title{
LA SENTENCIA DE INAPLICABILIDAD Y SU CUMPLIMIENTO POR PARTE DE LOS TRIBUNALES DE JUSTICIA*
}

\section{THE INAPPLICABILITY SENTENCE AND ITS COMPLIANCE BY THE COURTS}

\author{
Williams Eduardo Valenzuela Villalobos* \\ Universidad Andrés Bello \\ williams.valenzuela@unab.cl
}

RESUMEN: El trabajo analiza los efectos del fallo de inaplicabilidad y las consecuencias prácticas que generan para el juez de la gestión pendiente, quien ve alterada la legislación a aplicar, en el caso de mediar un fallo estimatorio. Lo anterior, puesto que está vinculado por el mandato prohibitivo o negativo que genera la sentencia del Tribunal Constitucional. Luego se revisa cómo han actuado los tribunales de justicia ante ello.

ABSTRACT: The article analyzes the effects of the inapplicability ruling and the practical consequences that they generate for the judge of the case, since the legislation to be applied is changed, in the event of a favorable decision. The foregoing, since it is linked by the prohibitive or negative mandate generated by the judgment of the Constitutional Court. To then review how the courts of justice have acted.

PALABRAS CLAVE: Acción de inaplicabilidad, Efectividad de la sentencia, Tribunal Constitucional. KEY WORDS: Inapplicability action, Sentence effectiveness, Constitutional Court.

\section{Planteamiento del problema}

La sentencia definitiva de inaplicabilidad constituye el acto procesal, irrecurrible e inalterable, que pone fin al proceso de inaplicabilidad y resuelve la cuestión constitucional planteada. La trascendencia del fallo se concreta en la medida en que se trate de una sentencia estimatoria, dado que en dicho caso cobra relevancia el estudio y sistematización de sus efectos temporales, personales y materiales. Asimismo, se debe destacar la importancia que ha adquirido el proceso de inapli-

\footnotetext{
* Trabajo recibido el 19 de marzo de 2018 y aprobado el 17 de enero de 2019.

** Académico Universidad Andrés Bello. abogado, licenciado en Ciencias Jurídicas y magíster en Derecho Constitucional y Derechos Humanos de la Universidad de Talca. Becario CONICYT cursando actualmente Programa de Doctorado en Derecho en la Universidad de los Andes. Correo electrónico: williams.valenzuela@ unab.cl.
} 
cabilidad, que representó en 2017 más de un $96 \%$ de los ingresos al Tribunal Constitucional $^{1}$, al cual, además, se le ha atribuido el carácter de remedio o amparo indirecto de derechos fundamentales ${ }^{2}$.

Como el propio texto constitucional señala, la consecuencia propia de una sentencia estimatoria de inaplicabilidad es la prohibición para el juez de la gestión pendiente de aplicar -solo en ese proceso- el precepto legal censurado de inconstitucionalidad, mas dicha norma mantiene su vigencia al interior del ordenamiento jurídico, la que como tal no pierde su vocación de aplicabilidad, en la medida en que se concreten los supuestos de hecho que la hacen operativa. Es decir, el precepto solo se entiende "derogado" respecto de la gestión que sirvió de presupuesto procesal para deducir el requerimiento. Así, la inaplicabilidad genera unos acotados efectos, que no son otros que dicho mandato prohibitivo al juez del fondo. De hecho, se debe señalar que el juez de la gestión pendiente es el principal destinatario del fallo estimatorio, por cuanto las partes del proceso de inaplicabilidad solo podrán controlar a posteriori si el juez, en definitiva, cumplió con lo dictaminado por el Tribunal Constitucional (efectividad de la sentencia), teniendo a su disposición los mecanismos procesales que la ley les franquea ${ }^{3}$.

Con todo, el asunto no es están pacífico, puesto que, en los más de diez años de ejercicio de esta potestad por parte del Tribunal Constitucional, existen numerosos casos en que el juez del fondo ha desconocido o soslayado el mandato prohibitivo que se deriva de la sentencia estimatoria. Con el objeto de dar cuenta de dichas situaciones, el presente trabajo se estructura de la siguiente forma: estudio de los principios que están en juego en materia de sentencias constitucionales; análisis de los efectos del fallo inaplicabilidad, y, finalmente, la forma en que los diversos tribunales de justicia han obrado de mediar una sentencia estimatoria de inaplicabilidad.

\footnotetext{
${ }_{1}$ La inaplicabilidad ha adquirido una importancia significativa desde 2006 a la fecha, ya que hoy constituye la mayor parte del trabajo que desarrolla el Tribunal Constitucional. En efecto, en 2015, de los 186 asuntos que ingresaron al tribunal, el $80,6 \%$ corresponde a requerimientos de inaplicabilidad; lo propio ocurrió en 2016 , con un $83,7 \%$ de los 357 asuntos, y en el último año, correspondiente a 2017 , con un 96,4\% de los 930 asuntos que ingresaron a la magistratura constitucional (fuente: TribunAl ConstituCiOnAL).

2 Ver en este sentido Cazor, Pica (2009).

3 De esta manera, el incumplimiento de la sentencia de inaplicabilidad por parte del juez de la gestión pendiente puede servir, según se refiera al asunto principal o cuestiones accesorias del litigio, de fundamento de un recurso de reposición, apelación, casación o queja.
} 


\section{PRinCiPIOS EN MATERIA DE SENTENCIAS CONSTITUCIONALES}

Para el cometido planteado, es adecuado referirse lacónicamente a determinados principios que se presentan o están en juego en materia de sentencias constitucionales. Así, Francisco Zúñiga ${ }^{4-5}$ enumera cuatro principios fundamentales en la materia, que corresponden al de congruencia, motivación, decisión colegial y eficacia.

El principio de congruencia hace referencia a la debida concordancia y armonía que debe existir entre la demanda (requerimiento o solicitud) y la sentencia o decisión del órgano jurisdiccional en cuestión. De esta forma, el tribunal deberá fallar de acuerdo a lo solicitado por el recurrente de que se trate (causa de pedir), no pudiendo ser el fallo calificado de ultra o extra petita. Con todo, "la única derogación o negación del principio de congruencia que debe admitirse afecta a la causa petendi -no al contenido y extensión del petitum - se funda en el 'interés público' que el proceso constitucional comporta, y que permite al juez constitucional fundamentar la sentencia en consideraciones diferentes a las alegadas en el petitum, sustrayéndose a la causa petendi"6. Lo anterior tiene expreso reconocimiento en la Ley Orgánica Constitucional del Tribunal Constitucional (en adelante, LOCTC), que, en su artículo 88, expresamente contempla tal hipótesis de excepción al principio de congruencia, al señalar que "excepcionalmente y por razones fundadas, el Tribunal podrá declarar la inconstitucionalidad de las normas cuestionadas basado unicamente en fundamentos constitucionales distintos a aquellos que han sido invocados por las partes en la litis. En este caso, deberá advertirles acerca del uso de ese posible precepto constitucional no invocado y permitirles así referirse a ello. Dicha advertencia podrá efectuarse en cualquier etapa del juicio, incluyendo la audiencia de la vista de la causa, cuando proceda, y también como medida para mejor resolver".

Continúa Zúñiga señalando -ahora- que el principio de motivación nos lleva al estudio de los vicios de inconstitucionalidad. De esta forma, un fallo de inconstitucionalidad puede ser fundado en los siguientes vicios: vicios materiales o sustantivos, vicios por defecto de competencia, vicios de forma o in procedendo, vicios en el ámbito de la actividad discrecional del poder legislativo y vicios por omisión.

4 ZÚNiga (2006), pp. 92-95.

5 Ver en este sentido también Nogueira (2009), pp. 475 y ss.

6 ZúNIGa (2006), p. 93. 
Como es sabido, es un punto pacífico en la jurisprudencia constitucional chilena que el vicio de inconstitucionalidad de que puede adolecer el precepto legal impugnado, en sede de inaplicabilidad, es de forma y fondo, a diferencia de la errónea jurisprudencia de la Corte Suprema, que, en determinado momento histórico, cuando ejercía tal potestad (antiguo art. 80, CPR), solo permitió el control de fondo del precepto censurado, dejando fuera del margen de control una gran cantidad de legislación irregular. En efecto, el Tribunal Constitucional ha sentenciado:

"Que, respecto del primer punto anunciado, la sentencia de este Tribunal, de diecisiete de noviembre de 2006 (rol No 546, Capitulo I), se refirió extensamente a la naturaleza de la actual acción de inaplicabilidad y sus diferencias con la similar prevista en la Carta Fundamental con anterioridad a la reforma del año 2005, destacando especialmente la constatación de que de la simple comparación del texto de la norma actual con el antiguo articulo 80 de la Carta Fundamental, que entregaba esta facultad a la Corte Suprema, se desprende que mientras antes se trataba de una confrontación directa entre la norma legal y la disposición constitucional, ahora se está en presencia de una situación diferente, por cuanto lo que podrá ser declarado inconstitucional, por motivos de forma o de fondo, es la aplicación del precepto legal impugnado a un caso concreto, lo que relativiza el examen abstracto de constitucionalidad, marcando asi una clara diferencia con la regulación prevista por el texto constitucional anterior"'

El principio de colegialidad o de decisión colegial, como lo llama Nogueira ${ }^{8}$, hace referencia al estatus del Tribunal Constitucional como órgano que actúa como un colegio de jueces ${ }^{9}$. El principio así establecido se vincula directamente con la manifestación de votos disidentes y prevenciones, los que expresamente están recogidos en forma obligatoria en la LOCTC.

Por su lado, el principio de eficacia envuelve dos tópicos: los efectos de la sentencia constitucional y la efectividad de la misma. En cuanto a los efectos, estos pueden ser analizados desde una perspectiva personal, donde el fallo puede vincular solo a las partes del conflicto constitucional (efectos inter partes) o producir efectos generales o erga omnes. Debe tenerse a la vista que los efectos relativos o inter partes son propios del modelo americano de control de constitucionalidad

7 Rol No 473, 8 de mayo de 2007, considerando 90.

8 Nogueira (2009).

9 En este sentido puede verse la obra de ZAGREBELSKY (2008). 
y los efectos generales, del sistema europeo de control ${ }^{10}$. Los efectos temporales pueden ser calificados de retroactivos (o ex tunc) o pro futuro, es decir, desde la dictación del fallo hacia adelante (o ex nunc). Asimismo, el efecto material hace referencia a la cosa juzgada de la sentencia constitucional, "tal concepto que tradicionalmente entraña irrevocabilidad de ciertos actos jurisdiccionales o inatacabilidad (J. Guasp), sea material o formal, y demás formas derivadas, no puede ser objeto de traslado mecánico a la Jurisdicción Constitucional"11.

La efectividad del fallo constitucional nos plantea la interrogante no menor sobre el cumplimiento y ejecución material de la sentencia. Como es sabido, la arquitectura constitucional no concedió facultad de imperio al Tribunal Constitucional, quedando entregado el cumplimiento del fallo -en los hechos- a la buena fe y vinculación directa de los demás órganos a la Constitución, conforme a la clásica fórmula consagrada en los artículos $6^{\circ}$ y $7^{\circ}$ de la Carta Fundamental. Para cerrar, el autor plantea que las sentencias exhortativas e interpretativas representan una herramienta por medio de la cual el Tribunal Constitucional refuerza la efectividad de sus decisiones ${ }^{12}$.

\section{EL FALLO DE INAPLICABILIDAD}

Para un acabado análisis de la sentencia de inaplicabilidad y sus efectos, es necesario repasar en qué consiste la institución de la inaplicabilidad, su naturaleza y sus características, como marco teórico indispensable para el objeto enunciado. De esta forma, el mal llamado recurso o acción de inaplicabilidad está encaminado a obtener una declaración del Tribunal Constitucional que prohíba la aplicación de determinado precepto legal relevante a una gestión judicial pendiente, ya que, de recibir aplicación, produciría efectos contrarios a la Constitución, salvaguardándose así la supremacía constitucional y la indemnidad de la Carta Fundamental.

El propio Tribunal Constitucional ha señalado que la competencia que el numeral $6^{\circ}$ del artículo 93 de la Constitución le entregó consiste precisamente en que:

"El Tribunal está llamado a determinar si la aplicación del precepto en la gestión específica resulta contraria a la Constitución. Lo que el Tribunal debe practicar es un examen

10 Ver en este sentido Valenzuela (2012), Capítulo I: 2.3.

11 ZúñIga (2006), p. 95.

12 ZúñIgA (2006), p. 95. 
concreto de si el precepto legal, invocado en una gestión judicial pendiente y correctamente interpretado producirá efectos o resultados contrarios a la Constitución"13.

Sobre la naturaleza y características de la acción de inaplicabilidad por inconstitucionalidad, se puede sostener lo siguiente ${ }^{14}$ :

i. Es una competencia privativa y excluyente del Tribunal Constitucional.

ii. Es una acción constitucional.

iii. La acción de inaplicabilidad está dirigida a impugnar preceptos legales concretos y determinados que en su aplicación produzcan efectos contrarios a la Constitución; es decir, el recurso posee una pretensión específica de que no se aplique un precepto legal a una causa determinada, por ser contrario a la Constitución. Cita PeNAA, a modo de ejemplo, lo que ha sostenido el propio Tribunal Constitucional respecto de esta característica: "la presente acción de inaplicabilidad se encuentra dirigida... contra diversos textos legales en su conjunto y de manera completa y genérica, lo cual ciertamente no es consistente con la filosofía de la acción de inaplicabilidad'15.

iv. Representa una modalidad de control concreto de constitucionalidad de la ley, pues lo que se pretende es la inaplicabilidad de un precepto legal a un caso concreto por ser contrario a la Constitución. Al respecto, la magistratura constitucional ha sostenido que "las características y circunstancias del caso concreto de que se trate, han adquirido en la actualidad una relevancia mayor de la que debia atribuirsele antes de 2005 pues, ahora, la decisión jurisdiccional de esta Magistratura ha de recaer en la conformidad o contrariedad con la Constitución que la aplicación del precepto impugnado pueda tener en cada caso concreto, lo que no implica necesariamente, una contradicción abstracta y universal con la preceptiva constitucional' 16. Dada la importancia de este punto, volveremos sobre él más adelante.

v. Produce efectos inter partes.

vi. Son sujetos con legitimación activa el juez y las partes de la gestión.

vii. Una sala conoce de su admisión a trámite y admisibilidad y el pleno resuelve el fondo de la acción.

viii. Los requisitos de admisibilidad del requerimiento están establecidos en la propia Constitución, sin perjuicio de lo que señala la LOCTC.

13 Rol No 480, 27 de junio de 2006, considerando $27^{\circ}$.

14 Sistematizado de Peña (2009) y de Pica (2012), pp. 66-68.

15 Rol No 654, 30 de mayo de 2007, citado por Peña (2009), p. 411.

16 Rol No 623, 10 de septiembre de 2007, citado por MASSMANN (2009), p. 267. 
ix. El ejercicio de la competencia, por parte del Tribunal Constitucional, limita con el mérito de la norma; es decir, es un control de derecho estricto, no pudiendo el tribunal pronunciarse sobre la justicia, oportunidad o conveniencia de la norma impugnada.

x. El recurso de inaplicabilidad no constituye una acción de amparo de derechos fundamentales ${ }^{17}$.

xi. La acción de inaplicabilidad produce un efecto negativo y otro positivo. El negativo se configura al acogerse la declaración de inaplicabilidad respectiva, ya que en dicho caso queda prohibido al tribunal que conoce de la gestión aplicar el precepto cuestionado, y el efecto positivo se genera cuando el tribunal desecha la acción de inaplicabilidad intentada y, por tanto, el juez es soberano en la determinación del derecho aplicable.

xii. La acción de inaplicabilidad no tiene por objeto sustituir la labor que le compete al legislador y al juez del fondo.

xiii. La inaplicabilidad está dirigida tanto a examinar la constitucionalidad de fondo como la de forma. El Tribunal Constitucional, en relación con lo anterior, ha señalado que "habiendo formulado la requirente cuestionamiento de forma $y$ fondo, se procederá, como ha sido la práctica invariable de este Tribunal, a analizar primeramente los presuntos vicios formales, por ser la fórmula que más se aviene con la razón, de estar viciado en su formación, el precepto legal impugnado no será tal $y$ deberá acogerse el requerimiento, por lo que carecerá de toda utilidad analizar, además, las inconstitucionalidades de fondo de que pudo adolecer" 18 .

xiv. La sentencia estimatoria es presupuesto procesal para el ejercicio de la acción de inconstitucionalidad del numeral 7o del artículo 93 de la Constitución.

Ahora bien, entrando en materia, para referirse a la sentencia de inaplicabilidad, necesario es tener en consideración que la Constitución Política dispone en el numeral 6o del artículo 93 que corresponde al Tribunal Constitucional "resolver, por la mayoría de sus miembros en ejercicio, la inaplicabilidad de un precepto legal cuya aplicación en cualquier gestión que se siga ante un tribunal ordinario o especial, resulte contraria a la Constitución". Asimismo, señala el inciso primero del artículo 92 de la LOCTC que "la sentencia que declare la inaplicabilidad solo producirá efectos en el juicio en que

17 Si bien no representa una acción directa de amparo de derechos fundamentales, no debemos olvidar que en ciertos casos opera como una vía indirecta de tutela de derechos fundamentales. En efecto, pueden consultarse como ejemplo los fallos roles $\mathrm{N}^{\circ}$ s. 781, 944 y 815. Puede verse en este sentido también PiCA (2012), p. 82, y CAZOR, PICA (2009).

18 Rol No 535, de 8 de mayo de 2007, citado por PeÑa (2009), p. 413. 
se solicite", lo que debe ser complementado por lo dispuesto en el artículo 94 de la Constitución. De dichas normas se desprenden los efectos y características de la sentencia de inaplicabilidad. De esta forma, la sentencia estimatoria de inaplicabilidad:

i. Produce efectos temporales ex tunc o pretéritos;

ii. Produce efectos personales inter partes o relativos;

iii. Produce un efecto negativo, cuyo destinatario principal es el juez a quo, quien tiene prohibido aplicar el precepto legal censurado, el que, con todo, mantiene su plena vigencia en el ordenamiento jurídico;

iv. Altera la legislación regular aplicable al proceso que sirve de presupuesto procesal;

v. Debe ser acordada por la mayoría de miembros en ejercicio del Tribunal Constitucional;

vi. Debe cumplir con los requisitos de los numerales $1^{\circ}$ a $6^{\circ}$ inclusive del artículo 170 del Código de Procedimiento Civil;

vii. Es de única instancia, no procediendo recursos en su contra, sin perjuicio de que puede el mismo tribunal, conforme a la ley, rectificar los errores de hecho en que hubiere incurrido;

viii. Tiene imperio ${ }^{19}$;

ix. Produce el desasimiento del tribunal, y

x. Goza de autoridad de cosa juzgada ${ }^{20}$.

En dicha, línea cabe señala que la propia magistratura constitucional ya desde 2008 se ha encargado de precisar tales efectos, cuando sentenció que:

"A las características ya referidas (respeto de la acción de inaplicabilidad) se añade el efecto exclusivamente negativo de la declaración de inaplicabilidad, que se traduce en que, decidido por esta Magistratura que un precepto legal es inaplicable en la gestión respectiva, queda prohibido al tribunal que conoce de ella, fundar su decisión en el mismo. En cambio, en caso de desecharse por esta Magistratura la acción de inaplicabilidad intentada, el tribunal llamado a resolver la gestión pendiente recupera en plenitud su facultad para determinar la norma que aplicará a la resolución del conflicto del que conoce"21-22.

19 "En parte, la obligatoriedad de la sentencia emana, primeramente, de la fuerza normativa y vinculante de la Constitución, y en otra parte, se vincula o depende de la autoridad y prestigio que logre el TC entre los jueces, con una práctica constitucional estimulante y razonada" [GÓMEz (2013), p. 62].

20 Tal afirmación no es del todo pacífica, como se verá más adelante.

21 Rol No 821, 1 de abril de 2008, considerando 6º . El agregado es nuestro.

22 Pueden verse en este sentido también los fallos roles $\mathrm{N}^{\circ}$ s. 1130, 821, 608 (609, 610, 611 у 612 acumulados) 707 y 2034. 


\section{III.I. Efectos temporales}

En la cuestión de inaplicabilidad, los efectos en el tiempo no están delimitados con la suficiencia precisión, como en materia de inconstitucionalidad, donde el propio texto constitucional señala, en el artículo 94, inciso tercero, que "el precepto declarado inconstitucional... se entenderá derogado desde la publicación en el Diario Oficial de la sentencia que acoja el reclamo, la que no producirá efecto retroactivo". Mas respecto a la inaplicabilidad existen serias dificultades técnicas y prácticas sobre la determinación precisa del momento en que se genera la prohibición para el juez del fondo de aplicar el precepto legal impugnado y declarado inaplicable.

Como se ha dicho, el efecto propio de la sentencia estimatoria de inaplicabilidad es suspender la aplicación de la norma legal impugnada respecto de la gestión que sirvió de base para solicitar su inaplicación, es decir, se altera el sistema de fuentes formales del derecho.

En dicha línea, cabe dejar establecido desde ya que la sentencia estimatoria de inaplicabilidad produce efectos retroactivos o ex tunc, pero se discute desde a lo menos tres puntos de vista el momento preciso en que se genera la prohibición de aplicar el precepto legal censurado. Conforme a lo anterior, el efecto se podría retrotraer: i) a la época en que la norma entró en vigencia; ii) a la fecha en se produjeron los hechos que hacen aplicable la norma cuestionada, o iii) al día en que se inicia la gestión pendiente. Lo anterior cobra importancia si recordamos lo preceptuado por el artículo 81 de la LOCTC, que señala que el requerimiento podrá ser presentado "en cualquier oportunidad procesal (de la gestión pendiente) en que se advierta que la aplicación de un precepto legal que pueda ser decisivo en la resolución del asunto resulta contraria a la Constitución"23.

La determinación, en definitiva, de dicha cuestión y la adopción de una u otra postura puede poner en peligro la eficacia prevista por el constituyente derivada respecto al establecimiento de una acción de inaplicabilidad con efectos inter partes y como mecanismo de control concreto de constitucionalidad que hoy, como se dijo, se ha transformado en una verdadera garantía jurisdiccional, a lo menos indirecta, de los derechos fundamentales.

Se cree, dadas las consecuencias que la Constitución previó para la decisión de inaplicabilidad (prohibición de aplicar el precepto legal cuestionado a la gestión pendiente), que el efecto en el tiempo que se le debe atribuir a la sentencia es aquel que concreta tal prohibición desde el momento en que se verifican los

23 El agregado es nuestro. 
supuestos de hecho de la norma que la hacen aplicable. Retrotraer los efectos a una etapa anterior es inoficioso, dado que la inaplicabilidad genera solo una consecuencia negativa (la inaplicación del precepto) respecto de un proceso judicial determinado, manteniendo la norma su plena eficacia, puesto que no se produce su expulsión o derogación del ordenamiento jurídico. Asimismo, si entendemos que el efecto es retroactivo desde el inicio de la gestión, se acotan los efectos ya restringidos de la inaplicabilidad, donde la norma cuestionada y cuya aplicación se encuentra prohibida, es aplicable al caso en cuestión desde una etapa anterior a su inicio, porque la ley recibe aplicación una vez que se verifican los supuestos de hecho que originan la gestión judicial pendiente, transformando la actividad del juez -generalmente- en un acto declarativo.

Lo anterior pareciera ser una cuestión de absoluta lógica y de no muy difícil comprensión. Con todo, un fallo de la Corte Suprema ${ }^{24}$ puso en tela de juicio tales conclusiones y los efectos vinculantes del fallo de inaplicabilidad. Así, en el caso denominado "Gómez Montoya con Corporación Administrativa del Poder Judicial', la Corte Suprema, revocando un fallo de la Corte de Valparaíso, discurrió respecto de la vinculación de los fallos de inaplicabilidad del Tribunal Constitucional y sobre sus efectos temporales, acogiendo una tesis, en una decisión cuestionable, de efectos pro futuro. En dicha línea, y bajo el prisma errado de la corte, se haría ilusorio el cumplimiento de la orden o efecto negativo que envuelve las sentencias estimatorias de inaplicabilidad. Debe tenerse en cuenta que los requerimientos de inaplicabilidad pueden ser deducidos en cualquier etapa del proceso (art. 81, LOCTC). De esta forma, si se recurriera de inaplicabilidad, pendiente de resolución la gestión judicial determinada ante un tribunal de alzada, donde se cuestionare la constitucionalidad de un precepto legal que fundó el fallo de primera instancia y el Tribunal Constitucional acogiere el requerimiento, la norma no podrá recibir aplicación por parte de dicho tribunal ad quem ${ }^{25}$. Situación similar ocurrió en el caso en comento, donde la inaplicabilidad se declaró una vez que ya había recibido aplicación la norma al caso concreto, puesto que la norma era el fundamento de un acto administrativo terminal. De esta forma, queda claro que acoger una tesis de efectos hacia el fututo o ex nunc, como indicó la Corte Suprema en el fallo en comento, afecta la efectividad de la declaración de inaplicabilidad, pues ni el constituyente ni el legislador orgánico establecieron un determinado momento

24 Corte Suprema, rol No 4518-2011, 30 de noviembre de 2011.

25 La situación se torna más compleja en el caso del recurso de queja. 
para su deducción, la que, en definitiva, se puede promover mientras penda la gestión judicial ante un tribunal ordinario o especial.

Por lo anterior, se comparten algunos pasajes del voto de minoría del fallo citado, que en el considerando segundo señaló:

"Que el fallo referido (de inaplicabilidad) tiene ineludible incidencia en el caso de estos autos.

Para resolver el recurso es útil recordar que la sentencia de inaplicabilidad es vinculante en el pleito de que se trate, en el sentido que la resolución no podrá justificarse en el precepto declarado inaplicable por inconstitucionalidad, porque la declaración del fallo dispone la prohibición de emplear el precepto en la decisión del asunto.

Por otra parte, a los efectos relativos a esta acción, la referida sentencia ha de entenderse que produce tal efecto desde que el precepto entró en vigencia, porque en esta ocasión se produjo la contradicción con la Constitución; y porque, razonando desde la función de la acción de inaplicabilidad, de no ser asi, perdería eficacia toda vez que los hechos muy probablemente resultarían ser acordes con la norma por causa de la declaración siempre posterior"26.

Con todo, pese a que nada se expresó, como se vio, respecto a los efectos en el tiempo del fallo de inaplicabilidad, no podemos olvidar el tenor expreso de la Constitución, que prescribe que es competencia del Tribunal Constitucional "resolver, por la mayoría de sus miembros en ejercicio, la inaplicabilidad de un precepto legal'. Dicho pasaje constitucional consagra una expresa prohibición para el juez o tribunal de la gestión pendiente, quienes, pese a mantener la facultad de determinar la ley de fondo aplicable al caso concreto, no podrán aplicar el precepto declarado inaplicable, aunque lo consideren como una norma decisoria litis. Dicha prohibición, retomando el tema de los efectos temporales, se estableció en términos absolutos, independientemente del momento en que se determine que han de computarse los efectos retroactivos del fallo de inaplicabilidad.

Finalmente, cabe hacer notar que la medida de suspensión del procedimiento, que puede decretar la sala respectiva, está en expresa conexión con el efecto retroactivo del fallo, resguardando una eventual declaración de inaplicabilidad con la cosa juzgada que se podría generar de seguir la tramitación normal la gestión pendiente ${ }^{27}$.

26 El agregado es nuestro.

27 "Por regla general, la sentencia estimatoria del control concreto y facultativo tiene fuerza de inaplicación de la norma a la gestión o conflicto que la motiva, con efectos temporales ex tunc y efectos personales inter 


\section{III.II. Efectos personales}

En forma expresa, la LOCTC estableció los efectos personales del fallo de inaplicabilidad, los que podemos calificar de relativos o inter partes. Dichos efectos se encuentra en armonía con el sistema de control reparador concreto que consagró la Constitución en el numeral $6^{\circ}$ del artículo 93. Así, el inciso primero del artículo 92 de la LOCTC prescribe:

"La sentencia que declare la inaplicabilidad sólo producirá efectos en el juicio en que se solicite".

En consecuencia, la sentencia del Tribunal Constitucional que acoge un requerimiento de inaplicabilidad es vinculante solo respecto de la gestión judicial pendiente (partes y juez) que sirvió de presupuesto procesal para la presentación del respectivo requerimiento. Dicha prohibición es una instrucción expresa para el juez del fondo, quien, pese a estimar aplicable un precepto determinado, se encuentra privado de tal potestad si media fallo estimatorio de inaplicabilidad, lo que se desprende con nitidez de una interpretación armónica, sistemática y finalista de los artículos 6º 7o, 76 y 93 No 6 de la Constitución Política de la República.

\section{III.III. Efectos procesales}

Es menester referirse al no menos complejo tema de la cosa juzgada constitucional. En efecto, debemos comenzar señalando que el fallo de inaplicabilidad produce cosa juzgada material y formal, es decir, representa un acto jurídico procesal del Tribunal Constitucional de única instancia, irrecurrible, inalterable $\mathrm{y}$ vinculante.

Andrés de la Oliva nos señala que la cosa juzgada material presupone la formal (inimpugnabilidad y firmeza) y consiste precisamente en una determinada fuerza vinculante del fallo, en otros procesos, y "a cualesquiera órganos jurisdiccionales (el mismo que juzgó u otros distintos), respecto de precisos aspectos del contenido de

\footnotetext{
partes, y en tal medida puede tener un alcance casatorio o revocatorio en el tribunal de la gestión, para lo cual tiene importancia que la sala del Tribunal una vez declarada la admisibilidad de la acción de inaplicabilidad disponga la medida cautelar de suspensión del procedimiento (gestión pendiente ante tribunal ordinario o especial), para poner a salvo la declaración de inaplicabilidad que pudiere decretar el órgano plenario frente a la cosa juzgada que ampara las sentencias (definitivas e interlocutorias, e incluso equivalentes) firmes y ejecutoriadas dictadas por el tribunal de la gestión” [ZúNíga (2006), p. 109].
} 
esas resoluciones (de ordinario, sentencias)"28. En materia procesal constitucional su concepción no difiere en lo absoluto, por cuanto esta es entendida como "el atributo, la calidad o la autoridad de definitividad o firmeza que adquieren las sentencias constitucionales; no es propiamente un efecto de la sentencia constitucional, sino una cualidad que pueden adquirir esos efectos" 29 . Asimismo, en esta puede ser absoluta o relativa. En efecto, "la existencia de una cosa juzgada relativa existirá en el caso que el respectivo Tribunal Constitucional, en el momento de hacer su análisis, no haya tenido en consideración determinadas hipótesis posibles de inconstitucionalidad del enunciado normativo" 30 y, por el contrario, será absoluta en el caso de que se consideren todas las hipótesis posibles.

Con todo, en nuestro sistema procesal constitucional encontramos una serie de normas que se refieren a la inimpugnabilidad de las resoluciones del Tribunal Constitucional, mas no a la "cosa juzgada" propiamente tal. En dicha línea, el artículo 94 de la Constitución dispone que:

"Contra las resoluciones del Tribunal Constitucional no procederá recurso alguno, sin perjuicio de que puede, el mismo Tribunal, conforme a la ley, rectificar los errores de hecho en que hubiere incurrido".

Precepto que es desarrollado por el artículo 41 de la LOCT. Asimismo, debe tenerse presente lo dispuesto en el artículo 90 de la misma norma, que acoge la doctrina de la inalegabilidad del mismo vicio:

"Resuelta la cuestión de inaplicabilidad por el Tribunal Constitucional, no podrá ser intentada nuevamente, por el mismo vicio, en las sucesivas instancias o grados de la gestión en que se hubiere promovido" 31.

De esta forma, cabe señalar que, pese a que el texto constitucional y la LOCTC no se refieren expresamente al instituto de la cosa juzgada, las sentencias del tribunal constitucional sí producen tal efecto, puesto que, como señala MACHADO, el mencionado artículo 94 constitucional hace expresa referencia a "la consagración de la inmutabilidad de la decisión por ausencia de recurso, lo que además se corresponde cabalmente con la definición de cosa juzgada que se puede

28 De la Oliva (2005), p. 103.

29 Ferrer, SÁnchez (2009), p. 240.

30 Nogueira (2005), p. 616.

31 No debemos olvidar también la causal del numeral $2^{\circ}$ del artículo 84 de la LOCTC. 
desprender del artículo 174 del Código de Procedimiento Civil chileno"32. Lo que, además, se ve reforzado por el artículo 84 No 2 de la LOCTC ${ }^{33}$, al disponer que el requerimiento de inaplicabilidad será declarado inadmisible "cuando la cuestión se promueva respecto de un precepto legal que haya sido declarado conforme a la Constitución por el Tribunal, sea ejerciendo el control preventivo o conociendo de un requerimiento, y se invoque el mismo vicio que fue materia de la sentencia respectiva". En dicha línea, es perfectamente configurable la triple identidad en las acciones de inaplicabilidad e inconstitucionalidad ${ }^{34}$ al tenor del artículo 177 del Código de Procedimiento Civil, lo que ha sido expresamente recogido en la jurisprudencia del Tribunal Constitucional al señalar, por ejemplo, que:

"De conformidad con lo señalado, este Tribunal está impedido de entrar a examinar la posible inaplicabilidad del artículo 161, No 10, del Código Tributario, por su posible contradicción con el artículo 83 de la Carta Fundamental, pues tal contradicción fue, precisamente, el vicio considerado y desechado por la sentencia de 30 de abril de 2002, a través del entendido que se ha recordado.

No obstante lo señalado, no es menos cierto que el requirente atribuye al artículo 161, $N^{o}$ 10, del Código Tributario otros vicios de constitucionalidad sobre los que no existe pronunciamiento específico de esta Magistratura (vulneración de los artículos 10, 19, $N^{o}$ s. $3^{\circ}$, incisos cuarto, quinto y sexto, $4^{\circ}$ y 5o, y 76 de la Constitución), de los cuales habrá que hacerse cargo, sin perjuicio de lo que se dirá en el acápite siguiente"35.

Con todo, lo afirmado no resulta del todo pacífico en la doctrina nacional, por cuanto se ha sostenido que el fallo estimatorio de inaplicabilidad produce cosa juzgada solamente formal y el que desestima la acción no produce cosa juzgada alguna. De esta forma, Emilio Garrote sostiene que "las sentencias emanadas del control constitucional de inaplicabilidad por parte del TCCh sólo producirían cosa juzgada formal en el evento que acoja la pretensión. La posibilidad de revisar a través de recursos lo decidido mediante sentencia resulta por regla general descartada en atención al rango del órgano jurisdiccional que la emite,

\footnotetext{
32 Machado (2017), p. 103.

33 Sobre dicho precepto legal se ha señalado que "es evidente que el referido artículo no puede significar en caso alguno una especie de petrificación de una determinada posición por parte del Tribunal Constitucional, puesto que es posible que cambie de posición frente a una nueva circunstancia de hecho o una nueva causa de pedir" [MACHADO (2017), p. 104].

34 Machado (2017), p. 107.

35 Rol No 1406-2009, 31 de diciembre de 2009, considerando $10^{\circ}$.
} 
cuyo pronunciamiento no son impugnables, pero es mutable mediante sentencia dictada en juicio diverso", agregando que "ahora si la acción de inaplicabilidad es desestimada sin duda no genera cosa juzgada, de manera que puede volver a plantearse la inconstitucionalidad, máxime si consideramos que lo que se declara inaplicable no es la norma misma, sino la interpretación del precepto legal que provoca efectos contrarios a la Constitución. En definitiva, en el caso de la inaplicabilidad son hipótesis de inconstitucionalidad que plantean las partes o el juez al TCCh, perfectamente puede suceder que las partes plantean una inaplicabilidad respecto de la aplicación de un precepto legal que jamás estuvo en la mente del juez del fondo aplicarlo a la gestión pendiente, en cuyo caso la decisión del intérprete Constitucional será inoficiosa" 36 .

En otras palabras, la sentencia de inaplicabilidad "produce un efecto de 'estar resuelto o decidido' para esa, 'gestión'. Esta cualidad tiene características que la diferencian de la cosa juzgada, aunque no en sus efectos, que son más amplios en la gestión. 'Resuelta' la cuestión, como ordena la LOCTC, la sentencia se debe respetar en todas las instancias, ya que los efectos se radican en la gestión y no se requiere la triple identidad, es decir, la inaplicación es independiente de las partes y de los jueces que intervengan (de hecho, los jueces no son parte). Si intervienen con posterioridad terceros, por ejemplo, haciéndose parte, también afecta lo decidido"37.

\section{III.IV. Fundamentos de la sentencia}

La sentencia de inaplicabilidad deberá cumplir con los requisitos de los números $1^{\circ}$ al 6º, inclusive, del artículo 170 del Código de Procedimiento Civil. De esta forma, deberá contener, entre otras, "las consideraciones de hecho o de derecho que sirven de fundamento a la sentencia y la enunciación de las leyes, y en su defecto de los principios de equidad, con arreglo a los cuales se pronuncia el fallo". Exigiéndose de esta manera un nivel adecuado de fundamentación, como es necesario de todo órgano que ejerce jurisdicción; mas la LOCTC consagra dos cuestiones adicionales a las que se les debe poner suficiente atención y cuidado.

Por una parte, el artículo 88 consagra la posibilidad de acoger el requerimiento por fundamentos constitucionales diversos a los considerados e invocados por las

36 Garrote (2012), p. 406.

37 Gómez (2013), p. 59. 
partes del proceso de inaplicabilidad. Si así lo hiciere, se exige que previamente -en cualquier etapa del proceso ${ }^{38}$ - se advierta de tal circunstancia a las partes y se les permita así referirse a ellos. De esta manera, el señalado artículo consagra dicha hipótesis en los siguientes términos:

"Excepcionalmente y por razones fundadas, el Tribunal podrá declarar la inconstitucionalidad de las normas cuestionadas basado únicamente en fundamentos constitucionales distintos a aquellos que han sido invocados por las partes en la litis. En este caso, deberá advertirles acerca del uso de ese posible precepto constitucional no invocado y permitirles así referirse a ello. Dicha advertencia podrá efectuarse en cualquier etapa del juicio, incluyendo la audiencia de la vista de la causa, cuando proceda, y también como medida para mejor resolver".

En segundo lugar, la LOCTC agrega otro requisito a la sentencia estimatoria de inaplicabilidad, la que, conforme al artículo 89, deberá especificar de qué modo la aplicación del precepto impugnado a la gestión pendiente resulta contraria a la Constitución.

Finalmente, el tribunal, en determinados casos, deberá pronunciarse sobre las costas. En consecuencia, si estamos en presencia de un requerimiento de parte y el fallo no acoge la inaplicabilidad, se impondrán a esta las costas, salvo que el tribunal declare que haya tenido motivo plausible para litigar ${ }^{39}$.

\section{III.V. Eficacia de la sentencia}

De todo lo anterior se observa que el constituyente derivado de 2005 consagró un efecto muy acotado del fallo de inaplicabilidad, lo que dista de otros modelos de control reparadores concretos, como es el caso español, donde en la cuestión de inconstitucionalidad, de acogerse, el fallo produce efectos generales desde la fecha de su publicación en el Boletín Oficial del Estado, o el caso italiano, con el juicio en vía incidental, que también genera efectos generales, expulsando el precepto del ordenamiento jurídico. Tal posibilidad no estuvo ajena en la discusión de la

38 Dicha circunstancia se puede verificar, por ejemplo, al momento de concluir los alegatos en la audiencia pública de vista de la causa, donde el tribunal invita a las partes a referirse a otros fundamentos constitucionales para-eventualmente- proceder a acoger el requerimiento en cuestión. Dicha circunstancia está expresamente recogida en el Auto Acordado sobre Ingresos, Formación de Tablas y Vista de las Causas (disposición 19a).

39 Conforme al artículo 104 de la LOCTC, "la ejecución de la sentencia, en lo relativo a las costas, se efectuará conforme al procedimiento ejecutivo establecido en el Código de Procedimiento Civil y conocerá de ella el Juez de Letras en lo Civil que corresponda, con asiento en la provincia de Santiago". 
reforma constitucional de 2005, donde el expresidente del Tribunal Constitucional Juan Colombo sostuvo que "el fallo de este organismo debe expulsar la norma del ordenamiento jurídico porque, de lo contrario, se produce una desigualdad absoluta entre dos personas que en un país se rigen por una misma Constitución. Para un sujeto que logró una sentencia favorable en un recurso de inaplicabilidad, esa ley no existe y no se le aplica, y para todo el resto de los chilenos esa ley es perfectamente constitucional, tiene que aceptarse y los tribunales tienen que aplicarla. De tal modo que en virtud de los principios de supremacía constitucional, de la concentración de la justicia constitucional y de igualdad ante la ley, ésta debe ser constitucional o inconstitucional y si es inconstitucional, tiene que serlo para todos y eliminarse del sistema" 40 .

Por lo anterior, cobra tanta relevancia la actuación del juez a quo, quien, en definitiva, es el que le dará eficacia a la sentencia estimatoria de inaplicabilidad, ya que es el principal destinatario, amén de lo prescrito en la Constitución Política de la República, de cumplir con el mandato negativo que comporta tal sentencia pudiendo las partes de la gestión pendiente solo controlar a posteriori lo obrado en el proceso de que se trate. Con todo, la situación se torna mayormente compleja en los casos en que la decisión la debe adoptar-por ejemplo- la Corte Suprema, puesto que no existe instancia u oportunidad procesal posterior para alzarse en contra de una decisión que soslaye o desconozca la sentencia de inaplicabilidad.

En dicha línea, parte de la doctrina ya ha venido advirtiendo de los posibles conflictos entre jurisdicciones común y constitucional y la posibilidad de desobedecer o desconocer la fuerza vinculante de la sentencia de inaplicabilidad pronunciada por el Tribunal Constitucional. En efecto, se ha sostenido que "de la simple lectura de las sentencias que resuelven la gestión pendiente, habiéndose pronunciado el TCCh, ya sea acogiendo o desestimando la inaplicabilidad, en ninguno de los considerando se hace la más mínima alusión a los fundamentos y razonamientos tenido en cuenta por el Intérprete Constitucional. Incluso fallándose en sentido contrario a la determinación del Intérprete Supremo. Cuestión que se produce no sólo a propósito de requerimientos de inaplicabilidad a petición de parte sino también de oficio por el juez que conoce del asunto. Sea que se trate de un tribunal ordinario o especial, dejando en entredicho la fuerza vinculante y el efecto de sus sentencias" 41 .

40 Historia del establecimiento de la Ley No 20.050, p. 309.

41 Garrote (2012), p. 422. 
Cabe ser enfáticos, ya que independientemente de la modalidad que adopte el requerimiento de inaplicabilidad, sea este como medida preventiva, es decir, se deduce en un estado procesal donde el juez a quo no ha aplicado la norma cuestionada, o como un requerimiento reparador, donde la norma cuestionada ha recibido aplicación, pero la gestión procesal se encuentra aún pendiente, puesto que no se ha puesto fin al proceso por medio de una resolución judicial que produzca cosa juzgada ${ }^{42}$, el efecto de la sentencia estimatoria de inaplicabilidad es exactamente idéntico: prohibir al juez aplicar el precepto legal censurado por causa de inconstitucionalidad. Asimismo, cabe señalar que la doctrina le atribuye a la sentencia estimatoria de inaplicabilidad unos efectos indirectos: "revocatorio y casatorio, en atención al efecto que la inaplicación tiene en la decisión judicial recaída en la cuestión principal o en las cuestiones incidentales o accesorias de la gestión pendiente" 43 .

En síntesis, se debe señalar que "en términos técnicos, la sentencia estimatoria de inaplicabilidad contiene un mandato al juez de la causa, en cuanto le impide dar aplicación al precepto tachado de inconstitucional. En este sentido, ella produce un vacío ad casum, retirando el o los preceptos impugnados del haz de normas que maneja el juez a quo para dar solución al caso. Sobre este particular efecto de la sentencia, cabe hacer presente que aunque no es competencia del Tribunal Constitucional dirigir la sentencia del juez del fondo más allá de los límites que marca su jurisdicción tasada sobre la constitucionalidad de la norma aplicable, es relativamente frecuente que esa Magistratura deslice juicios sobre el proceder judicial ante el vacío que crea la sentencia de inaplicabilidad" 44 .

\section{CUMPLIMIENTO DE LA SENTENCIA DE INAPLICABILIDAD POR} PARTE DE LOS TRIBUNALES DE JUSTICIA

Corresponde hacer ahora una revisión de la actuación de los jueces del fondo en aquellos casos que deben resolver de mediar una sentencia estimatoria de

\footnotetext{
42 En este sentido se ha dicho: "usando una licencia lingüística y jurídica, la sentencia estimatoria de inaplicabilidad puede tener un alcance revocatorio o, en su caso, casatorio, en el evento que en dicha gestión se haya dictado sentencia definitiva o interlocutoria fundada en el precepto legal declarado inaplicable ex post. Ello porque la sentencia que declara la inaplicabilidad conlleva un mandato para los jueces que se encuentren actualmente conociendo de la gestión, en sede de recursos de apelación o casación, de tal modo que dichos jueces deberán necesariamente revocar o casar en el fondo, incluso de oficio, dicha sentencia”, ZÚNIGA (2010-a).

43 ZÚNiga (2009), p. 424.

44 NÚÑEZ (2008), p. 133.
} 
inaplicabilidad, para lo cual se revisó la jurisprudencia de febrero de 2016 a febrero de $2018^{45}$. Como premisa, es posible establecer principalmente tres categorías de análisis: i) casos en que se cumple con el fallo de inaplicabilidad; ii) casos en que no se aplica el precepto, pero por motivos distintos a los contenidos en la sentencia de inaplicabilidad, y iii) casos en que se incumple el fallo de inaplicabilidad.

\section{IV.I. Casos en que se cumple el fallo de inaplicabilidad}

Esta categoría no requiere mayor análisis y detención, puesto que se trata de hipótesis donde el juez del fondo actúa conforme a derecho y cumple el mandato directo que se deriva de la sentencia estimatoria de inaplicabilidad no dando aplicación al precepto legal censurado. Una de las primeras sentencias que encontramos en la materia fue dictada por la Corte de Apelaciones de Valparaíso, que, el 4 de octubre de 2007, en cumplimiento de la sentencia pronunciada en el proceso de inaplicabilidad rol No 499-2006 ${ }^{46}$, sentenció que:

"Primero: Que consta de las copias autorizadas agregadas a estos antecedentes desde fojas 228 y siguientes, que en el recurso de inaplicabilidad por inconstitucionalidad rol No 499-2006 seguido ante el Tribunal Constitucional, dicho Tribunal declaró, precisamente en relación con esta causa, inaplicable el artículo 116 del Código Tributario, por ser contrario a la Constitución Politica de la República.

Segundo: Que, en consecuencia, se concluye que lo actuado por la Juez a quo en esta causa, carece de validez, por falta de un presupuesto procesal, lo que determina que actuando de oficio esta Corte, resolverá la nulidad consecuente en la forma como se dispone en lo resolutivo de esta sentencia".

Asimismo, en los primeros años de ejercicio de esta potestad por parte del Tribunal Constitucional se pueden consultar los siguientes fallos, donde se dio expreso cumplimiento a la sentencia de inaplicabilidad:

i. Corte Suprema, rol No 265-2006, de 30 de enero de 2007 (INA 555-2006 ${ }^{47}$ );

45 Dando cuenta este trabajo de los fallos estimatorios de inaplicabilidad y respecto de los cuales se pudo tener acceso a las gestiones pendientes ante el juez a quo.

46 Requerimiento de inaplicabilidad por inconstitucionalidad del artículo 116 del Código Tributario (hoy derogado), que permitía la delegación de facultades de los directores regionales del Servicio de Impuestos Internos, en relación con los artículos 6º, $7^{\circ}, 19$ No 3, inciso cuarto, 38 inciso 2º, 76 y 77 de la Constitución Política de la República.

47 Requerimiento de inaplicabilidad por inconstitucionalidad del artículo 116 del Código Tributario (hoy derogado), que permitía la delegación de facultades de los directores regionales del Servicio de Impuestos 
ii. Corte Suprema, rol No 37795-2006, de 28 de marzo de 2007 (INA 5542006 $\left.{ }^{48}\right)$;

iii. I. Corte de Apelaciones de Valparaíso, rol No 3385-2006, de 20 de junio de 2007 (INA 658-200649);

iv. Corte Suprema, rol No 166-2006, de 29 de noviembre de 2007 (INA 502-200650).

\section{IV.II. Casos en que el precepto no recibe aplicación,} pero por motivos distintos a la sentencia de inaplicabilidad

Sobre este punto, lo primero que se debe señalar es que si bien el precepto no se aplica, y, consecuencialmente, el requirente no ve amagados sus derechos, se trata de situaciones en que el juez a quo desatiende o no comprende a cabalidad los efectos de la sentencia estimatoria de inaplicabilidad. Lo anterior, prima facie, no genera mayores cuestionamientos; con todo, el juez de la gestión pendiente transita por una delga línea entre el cumplimiento de su mandato de conocer y resolver el asunto sometido a su conocimiento y la preceptiva constitucional que regla la inaplicabilidad, por cuanto, de mediar sentencia estimatoria, el juez, por ejemplo, no puede entrar a analizar si la norma declarada inaplicable es decisoria litis, cuestión que no le compete, ya que el precepto censurado está derogado, no existe, no tiene vocación de aplicabilidad para la gestión pendiente, conforme lo dispone expresamente el artículo 93 No 6 de la Constitución Política de la República.

Internos, en relación con los artículos 6o , 7o , 19, 38, 63, 64, 66, 76 y 77 de la Constitución Política de la República y el artículo 8 o de la Convención Americana de Derechos Civiles y Políticos (sic).

48 Requerimiento de inaplicabilidad por inconstitucionalidad del artículo 116 del Código Tributario (hoy derogado), que permitía la delegación de facultades de los directores regionales del Servicio de Impuestos Internos, en relación con los artículos $6^{\circ}, 7^{\circ}, 19 \mathrm{No}^{\circ}$, incisos cuarto y quinto, 38, inciso segundo, 76 , inciso primero y 77, inciso primero de la Constitución Política de la República.

49 Requerimiento de inaplicabilidad por inconstitucionalidad del artículo 116 del Código Tributario (hoy derogado), que permitía la delegación de facultades de los directores regionales del Servicio de Impuestos Internos, en relación con los artículos $6^{\circ}, 7^{\circ}, 19$ o $3,38^{\circ}$ inciso $2^{\circ}$ y 76 de la Constitución Política de la República.

50 Requerimiento de inaplicabilidad por inconstitucionalidad del artículo 116 del Código Tributario (hoy derogado), que permitía la delegación de facultades de los directores regionales del Servicio de Impuestos Internos, en relación con los artículos $6^{\circ}, 7^{\circ}, 19$ No 3 , incisos cuarto y quinto, 38 inciso segundo, 76 inciso primero y 77 inciso primero de la Constitución Política de la República. 
En efecto, la Corte Suprema, en los autos rol No 7779-2008 (INA rol No 1287$2008^{51}$ ), de 27 de octubre de 2009, no da aplicación al precepto declarado inaplicable, pero desatiende el efecto vinculante de la sentencia estimatoria de inaplicabilidad al razonar que el precepto censurado no es una norma aplicable al caso concreto, señalando:

"En consecuencia, y como lo señalara el Ministro del Tribunal Constitucional, don Enrique Navarro Beltrán, en su disidencia, el precepto en cuestión no resulta aplicable para la resolución del asunto sometido al conocimiento de esta Corte, pues no forma parte del estatuto jurídico que rige la relación contractual existente entre el reclamante y la Isapre mencionada".

En sentido similar se pronunció la misma Corte Suprema, en autos rol No 4481-2010 (INA 1348-200952), el 24 de septiembre de 2010. Con todo, este proceso llama más aún la atención, por cuanto la cuestión de inaplicabilidad fue presentada de oficio por la Corte de Apelaciones de Talca, que conoció del recuro de protección en primera instancia, procediendo en consecuencia a acoger el referido recurso, lo que fue revocado por la Corte Suprema. Entre sus fundamentos, el máximo tribunal señaló:

"Que respecto del recurrente, su contrato de salud fue suscrito el día 31 de enero del año 2001, esto es, con antelación a la vigencia de dicho cuerpo normativo. De ello se sigue que la norma declarada inaplicable por inconstitucional carece de imperio respecto del contrato que vincula al actor con la Isapre Masvida S.A. En efecto, el legislador expresamente exceptuó de la regulación contenida en el articulo 199 a aquellos contratos anteriores que habian incorporado las aludidas tablas de factores de sexo y edad, prescribiendo-como ya se consignó- que tratándose de dichas convenciones operará lo acordado al momento de su celebración. En consecuencia, el precepto en cuestión no resulta aplicable para la resolución del asunto sometido al conocimiento de esta Corte, pues no forma parte del estatuto jurídico que rige la relación contractual existente entre el reclamante y la Isapre mencionada".

51 Requerimiento de inaplicabilidad por inconstitucionalidad del artículo 199 del Decreto con Fuerza de Ley (Ministerio de Salud) No 1, de 2005, mediante el cual se censura la tabla de factores de riesgo por edad, ya que de recibir aplicación al caso sub lite, infringiría los numerales $9^{\circ}$ y 24 del artículo 19 de la Constitución Política de la República.

52 La Corte de Apelaciones de Talca, como medida para mejor resolver, requirió de oficio la declaración de inaplicabilidad por inconstitucionalidad del artículo 199 del Decreto con Fuerza de Ley (Ministerio de Salud) No 1 , de 2005, en relación con los numerales 9º y 24 del artículo 19 de la Constitución Política de la República. 
De otra parte, en la sentencia de la Corte de Apelaciones de Santiago pronunciada en el proceso rol No 4985-2002 (INA rol No 472-200653), de 29 de agosto de 2008, la corte no aplicó el artículo 116 del Código Tributario, pero no en mérito directo de la sentencia de inaplicabilidad, la que se tuvo como un mero fundamento más, sino que fue en virtud de la derogación tácita de las normas que permitían la delegación de facultades del "juez tributario", lo que habría sido confirmado, en palabras de la propia corte, en la sentencia de inconstitucionalidad del artículo 116 del Código Tributario. De esta forma, el juez de la gestión pendiente desatiende los efectos directos que emanan de la sentencia estimatoria de inaplicabilidad y, al mismo tiempo, desconoce lo expresamente dispuesto en el artículo 94 de la Constitución, sobre los efectos temporales pro futuro de la sentencia de inconstitucionalidad, cuando señala que el precepto censurado "se entenderá derogado desde la publicación en el Diario Oficial de la sentencia que acoja el reclamo, la que no producirá efecto retroactivo".

En igual sentido discurre la sentencia de la Corte de Apelaciones de Temuco del proceso rol No 715-2005 (INA rol No 628-200654), que, además, ni siquiera considera la sentencia estimatoria de inaplicabilidad que vinculaba su decisión; el fallo recaído en los autos rol No 1016-2006 (INA rol No 614-200655), también de la Corte de Temuco, y el fallo rol No 3240-2008 (INA rol No 1253-200856) del $3^{\circ}$ Juzgado Civil del Valparaíso.

Bajo este acápite también puede consultarse la sentencia de la Corte de Apelaciones de Santiago rol No 4502-2009 (INA rol No 1679-2001057), que fuera

53 Requerimiento de inaplicabilidad por inconstitucionalidad del artículo 116 del Código Tributario (hoy derogado), que permitía la delegación de facultades de los directores regionales del Servicio de Impuestos Internos, en relación con los artículos 6 $6^{\circ}, 7^{\circ}, 19$ No 3, inciso cuarto, 38 inciso $2^{\circ}, 76$ y 77 de la Constitución Política de la República.

54 Requerimiento de inaplicabilidad por inconstitucionalidad del artículo 116 del Código Tributario (hoy derogado), que permitía la delegación de facultades de los directores regionales del Servicio de Impuestos Internos, en relación con los artículos $6^{\circ}, 7^{\circ}, 19$ o 3 , incisos cuarto y quinto, 76 inciso primero y 77 inciso primero de la Constitución Política de la República.

55 Requerimiento de inaplicabilidad por inconstitucionalidad del artículo 116 del Código Tributario (hoy derogado), que permitía la delegación de facultades de los directores regionales del Servicio de Impuestos Internos, en relación con los artículos $6^{\circ}, 7^{\circ}, 19 \mathrm{No}^{\circ} 3$, incisos cuarto y quinto, 38 inciso $2^{\circ}, 76$, inciso primero y 77, inciso primero, de la Constitución Política de la República.

56 Requerimiento de inaplicabilidad por inconstitucionalidad de la parte final del inciso primero del artículo 171 del Código Sanitario (hoy derogado), que exigía consignación previa para reclamar de las multas, en relación con el artículo 19 No 3 de la Constitución Política de la República.

57 Requerimiento de inaplicabilidad por inconstitucionalidad del artículo 2331 del Código Civil, en relación con los artículos $1^{\circ}, 4^{\circ}, 5^{\circ}$, inciso segundo, $6^{\circ}$, inciso segundo, y $19, \mathrm{No}^{\circ} \mathrm{s} .1^{\circ}, 4^{\circ}$, y $26^{\circ}$, de la Constitución Política de la República. 
confirmada por la Corte Suprema. Sobre tal fallo se ha señalado que "en el caso Camiroaga la ratio decidendi para resolver la no aplicación del art. 2331 del Código Civil no es la sentencia estimatoria de inaplicabilidad sino la inexistencia de la injuria que sirve de premisa para la aplicación de dicho precepto legal. El razonamiento es simple: si no hay injuria desaparece la hipótesis de hecho de una norma que, aún sin fallo de inaplicabilidad, no podía ser aplicada en la gestión pendiente" 58 .

De otro lado, la misma Corte de Apelaciones de Santiago en fallo de 25 de abril de 2012, rol No 8063-2009 (INA rol No 1449-200959), señaló:

"Que, del análisis de los antecedentes recabados, aparece que no puede prosperar el recurso en cuanto se dirige en contra del Administrador General del Fondo Solidario de Crédito Universitario de la Universidad de Chile, precisamente porque no se ha proporcionado ningún elemento de juicio que permita concluir que dicho organismo solicitó a la Tesorería General de la República la retención de la devolución de impuestos correspondiente a la declaración de impuesto a la renta año 2009 del señor Espinosa Rojas. Por lo tanto, no tiene incidencia en el presente recurso lo decidido por el Tribunal Constitucional en la acción de inaplicabilidad por inconstitucionalidad ya referida, en la medida que la Tesorería General de la República al obrar de la manera de que da cuenta este expediente no dio aplicación a lo que dispone el artículo $1^{\circ}$ de la Ley No 19.989".

En síntesis, una vez declarado un precepto inaplicable el juez a quo no puede entrar a analizar la vigencia, eficacia o aplicabilidad de la norma declarada inaplicable, por cuanto la debe entender derogada respecto de la gestión pendiente que debe resolver, conforme al tenor expreso de la Carta Fundamental.

\section{IV.III. Casos en que no se cumple el fallo de inaplicabilidad}

Desconocer la eficacia vinculante directa de los fallos de inaplicabilidad representa una mala praxis institucional por parte de los tribunales de justicia, quienes, en definitiva, afectan la supremacía e indemnidad constitucional al desatender los efectos inconstitucionales que el Tribunal Constitución declaró como ciertos

\footnotetext{
58 NúNEZ (2012) p. 51.

59 Requerimiento de inaplicabilidad por inconstitucionalidad del artículo $1^{\circ}$ de la Ley № 19.989, que faculta a la Tesorería General de la República a retener de la devolución anual de impuestos a la renta que correspondiere a los deudores del crédito solidario universitario, en relación con los numerales $3^{\circ}$ y 24 de la Constitución Política de la República.
} 
y efectivos al acoger el respectivo requerimiento y, asimismo, afecta los legítimos derechos e intereses del requirente.

En dicha perspectiva, resulta importante dar cuenta de aquellos cosos donde el precepto censurado recibe plena aplicación en la gestión judicial pendiente, entre los cuales, cabe recordar el citado caso "Gómez Montoya con Corporación Administrativa del Poder Judicial”, donde la Corte Suprema señaló:

"Tercero: Que de esta forma la aplicación de la norma precedentemente transcrita fue hecha por la recurrida antes de la declaración de inaplicabilidad efectuada por el Tribunal Constitucional, de forma que se encontraba obligada a obrar como lo ordena ese mandato legal al no encontrarse el recurrente en ninguna de las hipótesis que permiten obtener los incrementos por desempeño institucional y colectivo, esto es encontrarse amparado por una licencia médica por accidente del trabajo. Así las cosas, la actuación de la recurrida que se impugna se agotó con la aplicación que en su momento hizo del artículo $4^{\circ}$ de la Ley No 19.531.

Cuarto: Que por consiguiente el hecho de que con posterioridad el Tribunal Constitucional haya declarado inaplicable el precepto legal en cuya virtud la Corporación Administrativa del Poder Judicial -entidad que se encuentra sujeta al principio de juridicidad-no pagó los bonos institucional y colectivo al recurrente, no implica que tal proceder sea ilegal, por lo que para estimar que obró en disconformidad con la normativa existente a la fecha del pago cuestionado es necesario que tal proceder sea retroactivamente considerado contrario a la ley aplicable al caso concreto en el momento de efectuarse el descuento de los bonos en la liquidación de sueldo del actor".

En igual sentido encontramos las sentencias de la Corte de Apelaciones de Santiago en los siguientes procesos:

i. Rol No 7767-2009, de 8 de octubre de 2010 (INA 1438-200960): “Que el Excmo. Tribunal Constitucional declaró inaplicable el artículo $1^{\circ}$ de la Ley $N^{\circ} 19.989$, pronunciamiento que tiene efecto inhibitorio respecto a esta Corte, en cuanto a que el citado precepto legal no puede ser considerado o aplicado por este Tribunal al resolver lo que en esta sede se ha propuesto.

Sin embargo, el recurso de protección de autos reprocha el actuar de la Tesorería General de la República que descontó de la devolución anual de impuestos a la renta del año 2008 del recurrente, a través del formulario 22, la suma de \$438.020 por

60 Requerimiento de inaplicabilidad por inconstitucionalidad del artículo $1^{\circ}$ de la Ley No 19.989, que faculta a la Tesorería General de la República a retener de la devolución anual de impuestos a la renta que correspondiere a los deudores del crédito solidario universitario, en relación con los numerales $2^{\circ}, 3^{\circ}$ y 24 de la Constitución Política de la República. 
concepto de deuda de crédito universitario, acto que al momento en que se ejecutó lo fue en cumplimiento de la obligación legal que al órgano administrativo le impuso la Ley $N^{\circ} 19.989$, de suerte que no cabe reprochar tal conducta hoy de ilegal'.

ii. Rol No 1437-2009, de 23 de junio de 2011 (INA 1437-200961): "Que, en primer lugar, se hace necesario consignar que la declaración de inaplicabilidad pronunciada por el Tribunal Constitucional, en sentencia de 7 de septiembre de 2010, cuya copia rola a fojas 42, no tiene influencia en la resolución de esta causa. En efecto, la Tesorería General de la República, recurrida en este proceso constitucional de naturaleza cautelar, aplicó el precepto legal cuestionado, artículo $1^{\circ}$ de la Ley $N^{o}$ 19.989, antes de que fuera declarado inaplicable por la Magistratura Constitucional. Aún más, puede decirse que se encontraba obligada a proceder conforme se lo ordena ese mandato legal al haber recibido de la entidad acreedora la comunicación respectiva". El último de dicho fallo fue confirmado por la Corte Suprema; sin embargo, encontramos el siguiente voto de minoría:

"20.- Que el fallo recién referido niega efecto retroactivo a la declaración de inaplicabilidad del artículo $1^{\circ}$ de la Ley $N^{\circ} 19.989$, en circunstancias que la sentencia de inaplicabilidad precisamente acogió esta pretensión en relación con este recurso de protección, que está motivado en la retención de las sumas correspondientes al pago provisional de impuestos fundamentada en dicha norma.

En concepto de estos disidentes dicho efecto es propio de la sentencia de inaplicabilidad, porque no puede sino que entenderse que la condición de inconstitucionalidad de la norma legal se presenta desde que contraviene la de carácter constitucional esto es, no desde la declaración de inaplicabilidad, colisión que inequivocamente tiene lugar cuando el precepto adquiere vigencia, cual es lo que el fallo simplemente verifica.

30.- Que a los efectos del recurso es útil recordar que la sentencia de inaplicabilidad es vinculante en el pleito de que se trate, en el sentido que la resolución no podrá justificarse en el precepto declarado inaplicable por inconstitucionalidad, porque la declaración del fallo dispone la prohibición de emplear el precepto en la decisión del asunto.

Toda vez que la retención de las sumas correspondientes a pago provisional mensual sólo se encuentra regulada en el precepto de que se trata, ha de inferirse que el acto que la

61 Requerimiento de inaplicabilidad por inconstitucionalidad del artículo $1^{\circ}$ de la Ley № 19.989, que faculta a la Tesorería General de la República a retener de la devolución anual de impuestos a la renta que correspondiere a los deudores del crédito solidario universitario, en relación con los numerales $2^{\circ}, 3^{\circ}$ y 24 de la Constitución Política de la República. 
dispuso y que es objeto de esta acción cautelar carece de sustento legal, porque no hay otro que también lo autorice"62.

Asimismo, encontramos la sentencia recaída en los autos rol No 4877-2007, de 2 de junio de 2009, donde la Excma. Corte Suprema incumple abiertamente el fallo de inaplicabilidad. En efecto, en sede de casación en el fondo, revisando una sentencia confirmada en segunda instancia, señala expresamente que el precepto declarado inaplicable recibió plena aplicación por el juez del fondo; con todo, como el recurrente no denunció la infracción del precepto declarado inaplicable, carece de facultades, dado que la casación en el fondo es un recurso de derecho estricto y no constituye instancia, para proceder a revisar la aplicación que se hiciera de tal norma. En dicha línea, señala que:

"Por el recurso no se ha denunciado la infracción al artículo $5^{\circ}$ de la Ley No 18.900 que es la norma que resuelve el caso y que conforme a la cual la sentencia de primer grado -aunque lo aplicó en su integridad-rechazó la demanda causándole agravio al recurrente, situación que mantiene el fallo impugnado de casación al confirmar aquélla.

Al no haberse denunciado infracción a esta decisoria litis debe concluirse que el recurrente la supone bien aplicada, lo que impide a esta Corte su revisión y conduce al necesario rechazo del presente recurso.

En efecto, la casación no es instancia y por el recurso de nulidad de fondo como el de la especie sólo es posible revisar la aplicación que los jueces del fondo han hecho de la ley pero en tanto cuanto sea denunciada su infracción, ya por contravención formal, ya por falsa aplicación o errónea interpretación. En la especie, nada de esto ha acontecido con la decisoria litis en comento por lo que no es posible revisar la aplicación que de la misma han hecho los sentenciadores del grado con la limitación establecida por el fallo del Tribunal Constitucional'.

Por su parte, en el proceso de inaplicabilidad rol No 2793-201563, el Tribunal Constitucional declaró inaplicable parte del artículo 5º de la Ley No 18.900 en el marco de un recurso de protección, razonando de la siguiente forma:

"Vigésimo Segundo: Que, a un tiempo, la aplicación que se ha dado a la norma legal refutada importa suspender, en la práctica, el pleno ejercicio del derecho constitucional de

62 Corte Suprema, rol No 6790-2011, de 20 de octubre de 2012.

63 Requerimiento de inaplicabilidad por inconstitucionalidad de la frase que indica, contenida en el inciso primero del artículo $5^{\circ}$ de la Ley $\mathrm{N}^{\circ} 18.900$, en relación con los artículos $1^{\circ}$, inciso tercero, y $5^{\circ}$, inciso final, de la Constitución Política de la República. 
propiedad que asiste a todos quienes depositaron su dinero en aquellas cuentas de ahorro administradas por el sistema, al encontrarse-ahora-privados del poder para reclamar al sujeto deudor la devolución efectiva del mismo.

Admitir que, en virtud de la parte cuestionada del artículo $5^{\circ}$ de la Ley $N^{\circ}$ 18.900, tales personas tendrian que esperar hasta que el Estado deudor se digne dictar el decreto aprobatorio de rigor, implicaría - en la realidad de las cosas-aceptar que por acto legislativo se puede anular aquello que, en tanto derecho y en cuanto propiedad, asegura el artículo 19, $N^{\circ} 24^{\circ}$, de la Constitución, dejándolo reducido a una mera declaración nominal y carente de significación concreta. Impedidas estas personas, como están, para hacerlo valer $y$ poderlo ejercer legitimamente, durante un ilimitado intertanto;

Vigésimo Tercero: Que, en efecto, dado que tal derecho fundamental comprende la facultad esencial para exigir aquello que la Constitución reconoce como tal, esto es, el poder jurídico para recuperar lo propio, en este caso y por contraste, la norma objetada priva al titular de la posibilidad para solicitar el retiro de sus haberes, al negar la correlativa garantía de que obtendrá la restitución de ellos.

Luego, entonces, al vedárseles acceder a lo suyo, los ahorrantes asi obstruidos se ven impedidos de ejercer los atributos y facultades esenciales del dominio que tienen sobre los valores de que son titulares, circunstancia que configura una privación notoriamente inconstitucional;

Vigésimo Cuarto: Que, se recordará, la Constitución de Chile sólo permite una única manera de privar a las personas de su propiedad, del bien sobre que recae o de alguno de los atributos o facultades esenciales del dominio: la ley general o especial que autorice tal expropiación, por causa de utilidad pública o de interés nacional calificada por la misma ley, y previo pago de las indemnizaciones que correspondan (inciso $3^{\circ}$ del citado artículo 19, $N^{\circ} 2^{\circ}$ ), requisitos que no satisface el artículo $5^{\circ}$ de la Ley $N^{\circ} 18.900$, en la parte impugnada.

Por lo demás, en este caso concreto no se advierten razones que justifiquen variar el criterio unánime sostenido, en este mismo sentido, por esta Magistratura Constitucional en la citada sentencia rol No 944-2008, donde justamente se acogió un requerimiento de inaplicabilidad dirigido contra la misma norma del artículo $5^{\circ}$ de la Ley $N^{o} 18.900$;

Vigésimo Quinto: Que, finalmente, comoquiera que la Ley No 18.900 vino a complementar la reseñada legislación sectorial precedente, a objeto de terminar el sistema y garantizar la devolución de sus ahorros a los depositantes impagos, su artículo $5^{\circ}$-en la parte reclamada-infringe asimismo el artículo 19, $N^{\circ} 26^{\circ}$, de la Constitución Politica.

Esto, al hacer precisamente lo que dicha regla constitucional impide: imponer una condición que impide el libre ejercicio del derecho de propiedad, según se ha explicado. 
A mayor abundamiento, debe consignarse que, a todo evento, la existencia de eventuales dificultades para liquidar el monto de lo adeudado, imputables únicamente a la parte deudora-Tesorería- no pueden ser obstáculo para la vigencia de la garantía del derecho de propiedad de la requirente".

No obstante ello, la Corte de Apelaciones de Talca, que conocía de la gestión pendiente, procedió a rechazar el amparo constitucional en el entendido de que el órgano público recurrido había actuado "conforme a la legalidad vigente". En efecto, señaló:

"Que, de lo reseñado en el fundamento anterior se infiere que la decisión de la Tesorería General de la República se enmarca en la legalidad vigente al 27 de noviembre de 2014, como tampoco que es arbitraria, toda vez que da razón de lo obrado, que se trata de una situación que afecta aproximadamente a setenta mil personas, no existiendo por ende discriminación ni capricho en la resolución adoptada por la recurrida" ${ }^{4}$.

En mérito de todo lo anterior, se puede sostener que, en el evento de que el juez de la gestión pendiente desatienda el mandato directo y vinculante que genera una sentencia estimatoria de inaplicabilidad, podrá el litigante en caso de tener remedios procesales disponibles, impugnar dicho fallo, ya que tal actuación sirve de fundamento para un recurso de reposición, apelación, casación o queja, según sea el caso.

\section{CONCLUSiones}

A modo de síntesis conclusiva se puede sostener que:

i. La sentencia estimatoria de inaplicabilidad produce un acotado efecto, consistente en modificar la legislación aplicable a la gestión judicial pendiente, por cuanto de ella se deriva directamente un mandato prohibitivo que impide considerar como norma aplicable al precepto legal censurado de inaplicabilidad. La norma no existe, la debemos entender derogada para la gestión; no obstante, mantiene su plena eficacia para el resto del ordenamiento jurídico.

ii. Tal efecto prohibitivo es relativo, retroactivo y produce el efecto de cosa juzgada.

iii. El juez de la gestión pendiente no puede considerar, bajo ninguna circunstancia, el precepto legal declarado como inaplicable como fundamento de su

64 Corte de Apelaciones de Talca, rol No 2495-2014, considerando 5º. 
decisión: sea para fundar autónomamente su inaplicación ni mucho menos para descartar la inaplicabilidad. Ello por expreso mandato constitucional, conforme expresa el numeral $6^{\circ}$ del artículo 93 de la Constitución Política de la República.

iv. El incumplimiento de la sentencia de inaplicabilidad sirve de fundamento, según sea el caso concreto, para fundar un recurso de reposición, apelación, casación o queja, sea que se trate del asunto litigioso principal o de cuestiones accidentales o accesorias de la gestión pendiente.

v. El juez a quo es siempre soberano para determinar el factum y el derecho material a aplicar, con la limitación arriba anotada, en el caso de mediar una sentencia estimatoria de inaplicabilidad.

\section{BibliografíA}

BRAZ Rodrigues, Jaana (2012): "Cuestiones prácticas de la tramitación del recurso de inaplicabilidad”, en Silva Gallinado, M. Pía; Henríquez Viñas, Miriam (Coords.): Derechos fundamentales y justicia constitucional (Santiago de Chile, Editorial LegalPublishing), pp. 209-224.

Cazor Aliste, Kamel (2011): "Casos paradigmáticos de la acción de inaplicabilidad como amparo imperfecto: Sentencias roles No 781, 808 y 1201”, en Marshall Barberán, Pablo (Coord.), Jurisprudencia constitucional destacada. Análisis crítico (Santiago de Chile, LegalPublishing), pp. 239-254.

Cazor Aliste, Kamel; Pica Flores, Rodrigo (2009): "Tribunal constitucional y control concreto en Chile: ¿Evolución hacia un amparo imperfecto?”, en Nomos (No 3), pp. 13-39.

Colombo Campbell, Juan (2009): "El requerimiento de inaplicabilidad ante el Tribunal Constitucional", en AA. VV., Temas actuales de derecho constitucional. Libro homenaje al profesor Mario Verdugo Marinkovic (Santiago de Chile, Asociación Chilena de Derecho Constitucional, Editorial Jurídica de Chile), pp. 53-74.

(2005): “Tribunal Constitucional: Integración, competencia y sentencia”, en Zúñiga Urbina, Francisco (Coord.), Reformas constitucionales (Santiago de Chile, Editorial LexisNexis), pp. 551-592.

(2002): "Funciones de derecho procesal constitucional", en Revista Ius et Praxis (Año 8, No 2), pp. 11-69.

CORREA SuTIL, Jorge (2011): Inaplicabilidad por inconstitucional en la jurisprudencia del Tribunal Constitucional (Santiago de Chile, Editorial LegalPublishing). 
Couso Salas, Javier; Coddou MacManus, Alberto (2010): “La naturaleza jurídica de la acción de inaplicabilidad en la jurisprudencia del Tribunal Constitucional: Un desafío pendiente", en Revista Estudios Constitucionales (Año 8, No 2), pp. 389-430.

De la Oliva Santos, Andrés (2005): Objeto del proceso y cosa juzgada en el proceso civil (Madrid, Editorial Thomson Civitas).

Fermandois Vohringer, Arturo (2005): "Efecto vinculante de las sentencias del Tribunal Constitucional: ¿Mito o realidad?”, en Zúniga Urbina, Francisco (Coord.), Reformas Constitucionales (Santiago de Chile, Editorial LexisNexis).

FERrada BóRquez, Juan Carlos (2001): "Las renuncias y vacilaciones del Tribunal Constitucional en la protección de los derechos fundamentales: Comentario a propósito de la STC Rol 1133/08”, en Marshall Barberán, Pablo (Coord.), Jurisprudencia constitucional destacada. Análisis crítico (Santiago de Chile, Editorial LegalPublishing), pp. 291-213.

Ferrer Mac-Gregor, Eduardo; Sánchez Gil, Rubén (2009): "Cosa juzgada y precedente en la acción de inconstitucionalidad mexicana”, en Anuario de Derecho Constitucional Latinoamericano (No XV), pp. 239-260.

García Pino, Gonzálo (2012): "Estudios sobre jurisdicción constitucional, pluralismos y libertad de expresión", en Cuadernos del Tribunal Constitucional (No 49).

Garrote Campillay, Emilio (2012): "Cosa juzgada constitucional sui generis y su efecto en las sentencias del Tribunal Constitucional en materia de inaplicabilidad e inconstitucionalidad", en Revista Estudios Constitucionales (Vol. 10, No 2), pp. 391-428.

Garrote Campillay, Emilio; Carrasco Poblete, Jaime (2011): "Legitimación en el proceso constitucional de inaplicabilidad a partir de la Ley de Reforma Constitucional No 20.050”, en Arancibia Mattar, Jaime; Martínez Estay, J. Ignacio; Romero Seguel, Alejandro (Coords). Litigación pública (Santiago de Chile, Editorial LegalPubliching), pp. 151-180.

Gómez Bernales, Gastón (1998): "Algunas ideas críticas sobre la jurisdicción constitucional en Chile", en Revista Ius et Praxis (Año 4, No 1), pp. 269-278. (2013): Las sentencias del Tribunal Constitucionaly sus efectos sobre la jurisdicción común (Santiago de Chile, Ediciones Universidad Diego Portales).

HenríqueZ Viñas, Miriam (2012): “¿Las normas derogadas pueden ser declaradas inaplicables por incostitucionalidad?”, en Silva Gallinado, M. Pía; Henríquez 
Viñas, Miriam (Coords.): Derechos fundamentales y justicia constitucional (Santiago de Chile, Editorial LegalPublishing), pp. 197-208.

Machado Martins, Priscila (2017): La cosa juzgada constitucional (Madrid, Reus). Martínez Estay, José Ignacio (2005): "Recurso de inaplicabilidad, Tribunal Constitucional y juez ordinario en la reforma constitucional", en Nogueira Alcalá, Humberto (Coord.), La Constitución reformada de 2005 (Santiago de Chile, Cecoch, Editorial Librotecnia), pp. 457-472.

Massmann Bozzolo, Nicolás (2009): "La admisibilidad del recurso de inaplicabilidad: A tres años de la reforma", en Revista Ius et Praxis (Año 15, No 1), pp. 263-293.

Navarro Beltrán, Enrique (2011): "El control de constitucionalidad de las leyes en Chile (1811-2011)", en Cuadernos del Tribunal Constitucional (No 43).

(2009): "La justicia constitucional chilena después de la reforma de 2005 (notas sobre la inaplicabilidad de las leyes y el recurso de protección)", en Nogueira Alcalá, Humberto (Coord.), La ciencia del derecho procesal constitucional. Estudios en homenaje a Héctor Fix-Zamudio en sus cincuenta años como investigador del derecho (Santiago de Chile, Editorial Librotecnia), pp. 203-228.

Nogueira AlcalÁ, Humberto (2012): "Los desafíos del control de convencionalidad del corpus iuris interamericano para los tribunales nacionales, en especial, para los tribunales constitucionales”, en Nogueira Alcalá, Humberto (Coord.), El diálogo transjudicial de los tribunales constitucionales entre si y con las cortes internacionales de derechos humanos (Santiago de Chile, Cecoch, Editorial Librotecnia), pp. 279-358.

(2005): "El control represivo concreto y abstracto de inconstitucionalidad de las leyes en la reforma constitucional de 2005 de las competencias del Tribunal Constitucional y los efectos de sus sentencias", en Zúñiga Urbina, Francisco (Coord.), Reformas constitucionales (Santiago de Chile, Editorial LexisNexis), pp. 593-626.

(2010): "El control reparador de constitucionalidad de los tratados internacionales en la sentencia del Tribunal Constitucional sobre ley adecuatoria de LOC del Tribunal Constitucional de 2009", en Nogueira Alcalá, Humberto (Coord.), Temas de derecho procesal constitucional. Reflexiones jurídicas sobre competencias del Tribunal Constitucional y la nueva LOC del Tribunal Constitucional (Santiago de Chile, Cecoch, Editorial Librotecnia), pp. 85-146. 
(2009): El derecho procesal constitucional y la jurisdicción constitucional en Latinoamérica y sus evoluciones (Santiago de Chile, Cecoch, Editorial Librotecnia).

Núñez Poblete, Manuel Antonio (2012): "Los efectos de las sentencias en el proceso de inaplicabilidad en Chile: Examen a un quinquenio de la reforma constitucional", en Revista Estudios Constitucionales (Año 10, No 1), pp. 15-64.

(2011): "Las representaciones internas del derecho internacional. Control preventivo e inaplicabilidad de los tratados internacionales en la jurisprudencia del Tribunal Constitucional”, en Marshall Barberán, Pablo (Coord.), Jurisprudencia constitucional destacada. Análisis crítico (Santiago de Chile, LegalPublishing), pp. 19-43.

(2010): "Sobre la declaración de inaplicabilidad de los tratados internacionales. Un estudio en defensa de su fundamento y legitimidad", en Revista Estudios Constitucionales (Año 8, No 2), pp. 431-464.

PeÑA Torres, Marisol (2009): "Inaplicabilidad por inconstitucionalidad: Reciente jurisprudencia del Tribunal Constitucional chileno", en Nogueira Alcalá, Humberto (Coord.), La ciencia del derecho procesal constitucional. Estudios en homenaje a Héctor Fix-Zamudio en sus cincuenta años como investigador del derecho (Santiago de Chile, Editorial Librotecnia), pp. 397-420.

Pérez Tremps, Pablo (2005): "La cuestión de inconstitucionalidad en el derecho español”, en Revista Estudios Constitucionales (Año 3, No 1), pp. 127-148.

PICA F., Rodrigo (2012): Control jurisdiccional de constitucionalidad de la ley en Chile: Los procesos de inconstitucionalidad y de inaplicabilidad por inconstitucionalidad de competencia del Tribunal Constitucional, 2a Ed. (Santiago de Chile, Ediciones Jurídicas de Santiago).

Quinzio FigueIredo, Jorge (2003-2004): Tratado de derecho constitucional, Tomo I (Santiago de Chile, Editorial LexisNexis).

Ríos Álvarez, Lautaro (2009): "La jurisdicción constitucional en Chile (después de la reforma de 2005 de la ley fundamental)", en Nogueira Alcalá, Humberto (Coord.), La ciencia del derecho procesal constitucional. Estudios en homenaje a Héctor Fix-Zamudio en sus cincuenta años como investigador del derecho (Santiago de Chile, Editorial Librotecnia), pp. 443-484.

(2005-a): "El nuevo Tribunal Constitucional”, en Zúñiga Urbina, Francisco (Coord.), Reformas constitucionales (Santiago de Chile, Editorial LexisNexis), pp. 627-650. 
(2005-b): "Trascendencia de la reforma constitucional en la fisonomía y las atribuciones del Tribunal Constitucional”, en Gaceta Jurídica (No 299), pp. 25-43.

SaEnger Gianoni, Fernando (2009): "Control abstracto y concreto en la nueva inaplicabilidad”, en AA. VV., Temas actuales de derecho constitucional. Libro homenaje al profesor Mario Verdugo Marinkovic (Santiago de Chile, Asociación Chilena de Derecho Constitucional, Editorial Jurídica de Chile), pp. 277-304. Saenger Gianoni, Fernando; Bruna Contreras, Guillermo (2006): Inaplicabilidad por inconstitucionalidad jurisprudencia 1980-2005 (Santiago de Chile, Editorial Jurídica de Chile).

VALENZUela V., Williams (2012): El control reparador de constitucionalidad de las normas legales: Un análisis comparativo de los tribunales constitucionales de Chile e Italia (Santiago de Chile, Ediciones Jurídicas de Santiago).

Zagrebelsky, Gustavo (2008): Principios y votos. El Tribunal Constitucional y la política (Traducc. de Manuel Martínez Neira, Madrid, Editorial Trotta).

ZúÑIgA Urbina, Francisco (2012): "Control de convencionalidad y tribunales nacionales. Una aproximación crítica”, en Nogueira Alcalá, Humberto (Coord.), El diálogo transjudicial de los tribunales constitucionales entre si y con las cortes internacionales de derechos humanos (Santiago de Chile, Cecoch, Editorial Librotecnia), pp. 387-448.

(2010-a): Acciones de inaplicabilidad e inconstitucionalidad. Doctrina y jurisprudencia del Tribunal Constitucional sobre temas procesales (Santiago de Chile, Editorial LegalPublishing).

(2010-b) "El principio pro requirente en la sentencia del Tribunal Constitucional sobre la Ley Orgánica Constitucional del Tribunal Constitucional", en Nogueira Alcalá, Humberto (Coord.), Temas de derecho procesal constitucional. Reflexiones jurídicas sobre competencias del Tribunal Constitucional y la nueva LOC del Tribunal Constitucional (Santiago de Chile, Cecoch, Editorial Librotecnia), pp. 161-190.

(2010-c) "La relación Tribunal Constitucional-tribunales del fondo y los efectos de la sentencia de inaplicabilidad acerca de los presupuestos de la acción”, en Nogueira Alcalá, Humberto (Coord.), Temas de derecho procesal constitucional. Reflexiones jurídicas sobre competencias del Tribunal Constitucional y la nueva LOC del Tribunal Constitucional (Santiago de Chile, Cecoch, Editorial Librotecnia), pp. 263-353. 
(2006): "Control de constitucionalidad y sentencia", en Cuadernos del Tribunal Constitucional (No 34).

(2005): "Control concreto de constitucionalidad: Recurso de inaplicabilidad y cuestión de constitucionalidad en la reforma constitucional", en Nogueira Alcalá, Humberto (Coord.), La Constitución reformada de 2005 (Santiago de Chile, Cecoch, Editorial Librotecnia), pp. 405-420.

ZúNíga Urbina, Francisco; Vega Méndez, Francisco (2006): "El nuevo recurso de inaplicabilidad por inconstitucionalidad ante el Tribunal Constitucional. Teoría y práctica”, en Revista Estudios Constitucionales (Año 4, No 2), pp. 134-174. 